\title{
Liver metastases of colon cancer. New therapeutic approaches. Neoadjuvant chemotherapy
}

\author{
A. Ruiz-Casado ${ }^{1}$, F. Pereira ${ }^{2}$
}

\section{Summary}

Colon cancer witnesses one of most exciting and evolving times in the latest years. About $30 \%$ of patients with isolated liver colon metastases can now be cured through a multidisciplinary approach of the disease. New systemic treatments have moved the median survival of metastatic disease from 12 months four years ago to 20 months and beyond. Incorporation of new biologic treatments into the neoadjuvant setting may help to further improve historical outcomes and offers promise to continue this trend.

Appropriate surrogate endpoints and optimal designs of clinical trials on neoadjuvant therapy as first or second-line of treatment are needed.

Key words:

Liver metastases. Colon cancer. Neoadjuvant chemotherapy.

Oncología, 2006; 29 (1):3-15

\footnotetext{
${ }^{1}$ Department of Medical Oncology

${ }^{2}$ Department of Surgery

Hospital de Fuenlabrada

Fuenlabrada (Madrid) España
}

Recibido: 16.07.2005

Aceptado: 19.07.2005 


\section{Resumen}

El cáncer de colon está presenciando en los últimos años un desarrollo científico espectacular. Aproximadamente el 30\% de los pacientes con metástasis hepáticas como única localización, pueden curarse actualmente con un planteamiento multidisciplinar de la enfermedad. Los tratamientos sistemáticos han desplazado la mediana de supervivencia de los 12 meses que se alcanzaban hace cuatro años a 20 meses e incluso más allá. La incorporación de nuevos tratamientos biológicos en el contexto de los tratamientos neoadyuvantes, podría mejorar los resultados históricos y mantiene la esperanza de que prosiga esta tendencia.

Se considera esencial un diseño correcto de los ensayos clínicos y la elección de objetivos apropiados, con tratamientos tanto en primera como en segunda línea, administrados con intención neoadyuvante.

Palabras clave: Metástasis hepáticas. Cáncer de colon. Quimioterapia neoadyuvante.

Nearly half of all patients with colon cancer will develop liver metastases and many will die with disease confined to the liver. The treatment of metastatic colorectal cancer has changed dramatically over the last ten years. The use of systemic therapy as a neoadjuvant treatment for patients with colon hepatic metastases is a relatively new approach and combination chemotherapy has gained wide acceptance as first line reference. Until the availability of the new drugs such as irinotecan and oxaliplatin, the efficacy of chemotherapy was so low that made such a strategy illogical. The emerging data with the new combinations, including new drugs like bevacizumab or cetuximab suggest a second dramatic step-up in antitumour efficacy, making up one of most exciting scenarios of our days.

In 2005, nearly one third of patients with disease confined to the liver can look forward to possibly curative liver surgery. A strategy of sequenced multiple treatments are moving the treatment of colorectal liver metastases to a new multidisciplinary medico-surgical field ${ }^{1}$.

\section{Anatomical basis and natural history of liver metastases}

The liver is the largest internal organ in the body, accounting for 2 to $3 \%$ of the total weight of an adult. Cancer cells travelling by hematogenous spread, have a high likelihood of arriving and lodging within the sinusoids of the liver. The liver is also the first major organ reached by venous blood draining from the gastrointestinal tract, and hence the most common site for distant metastatic disease in colon cancer, partly as a result of portal venous drainage of the gastrointestinal tract. The liver bleeds copiously and it is often the first organ to be injured in blunt abdominal trauma. To balance these negative characteristics it has two great attributes: its ability to regenerate after massive loss of substance, as well as its ability to forgive insult. A good knowledge of the anatomy is a prerequisite for modern surgery of the liver. Based on external appearance, four lobes are traditionally described: right, left, quadrate and caudate. Based on arterial and portal venous blood supply, biliary and hepatic venous drainage, the liver is divided into functional lobes and segments. The best known and most widely employed conceptions of hepatic segmentation are those of Couinaud (1954), those of Healy and Schroy (1953), simplified by Goldsmith and Woodburne (1957), and those of Bismuth (1982) ${ }^{2}$. Recently, a new terminology called the Brisbane 2000 Terminology of Liver Anatomy and Resections has been unanimously recommended and accepted by the scientific committee of the International Hepato-Pancreato-Biliary Association in order to resolve the existing confusion ${ }^{3}$.

Each one out of the 8 anatomic segments of the liver has an independent biliary drainage and vascular inflow and outflow. Consequently an individual segment can be removed without disrupting the blood flow or biliary drainage of the remaining segments.

Approximately $50 \%$ of patients with colorectal 
cancer develop liver metastases and $20 \%$ present with liver involvement at the time of diagnosis ${ }^{4}$. Interestingly, in some $20-35 \%$ of patients with advanced disease, metastases are confined to the liver ${ }^{5}$. Several retrospective studies have indicated that the outcome for patients with untreated liver metastases is poor, with a median survival of 8-12 months ${ }^{6,7}$. However, there are occasional long-term survivors and considerable disparity between mean and median survival. The factors that independently predict outcome on multivariate analysis are: performance status, extent of liver disease, abnormal liver tests and site of primary tumour ${ }^{8}$. In general, patient factors (i.e., gender or age) do not influence survival, whereas factors reflecting tumour burden (i.e. performance status) do.

\section{Treatment of liver-only metastases}

Surgical resection of liver-only metastases, where feasible, offers a significant survival advantage and should be considered for selected patients. Some have criticized that the improved survival rate seen in patients with resection (versus no resection) could be due to the superior performance and low tumour burden and therefore more favourable prognosis in patients considered for resection. Unfortunately, a randomized clinical trial will not be possible anymore given the compelling results for liver surgery, that seem to confer a survival benefit by itself ${ }^{9}$. The modern era has ushered in an aggressive approach to liver surgery because of the advances in imaging modalities, improved anaesthetic management, enhanced knowledge of functional liver anatomy and an appreciation of the functional reserve of the liver as well as the vast potential for hepatic regeneration. A number of issues remain subject to debate, including criteria for operability or nonresectability, optimizing surgical outcome with neoadjuvant or adjuvant therapy and the role of other regional therapies including hepatic arterial infusion of chemotherapy.

The goal of the pre-operative evaluation is to identify the best candidates for resection and to discriminate these from those with limited survival benefit or those who will be found at the operation to have unresectable disease. Whereas age alone is not a contraindication to resection, comorbid diseases may preclude major surgical resection. An evaluation to exclude the presence of extrahepatic disease should be done. The overall detection rate of helical $\mathrm{CT}$ in detecting colorectal liver metastases is approximately $85 \%$ and the positive predictive value is $96 \%{ }^{10}$. It is the imaging modality used most frequently to assess the extent of disease both within and outside the liver. MRI can distinguish benign cysts or hemangiomas from malignant lesions. FDG-PET scanning identifies additional disease or excludes metastases in $20 \%$ of patients ${ }^{11}$. CEA and Ca 19.9 must also be determined.

A conceptual approach would support the idea of administering systemic chemotherapy for all patients before surgery. The theoretical disadvantage would be the possibility of progressing to an unresectable situation. Of note, it seems that patients who progress to chemotherapy have anyway a poor prognosis ${ }^{12,13}$. The fact is that some multidisciplinary teams are using neoadjuvant therapy even if the resection is technically feasible (at least for synchronous metastases), in order to control the systemic disease. Tumour control before surgery is crucial to offer a chance of prolonged remission in patients with multiple metastases. Optimal sequencing of systemic and local therapy remains an area of active debate.

\section{Ablative and destructive therapies}

The description of these techniques exceeds the purpose of this review. However it should be mentioned that they are very useful when surgery is not possible or sometimes as a complementary treatment. Radiofrequency ablation uses high-frecuency alternating current to produce heat. It has proven to be an extremely safe procedure with complication rates of less than $10 \%$, being very useful for small lesions ${ }^{14}$. It is contraindicated in the proximity of the principal biliary ducts. It can be performed percutaneously, laparoscopically or even through open laparotomy, having replaced other ablative techniques as the preferred method of interstitial ablation. For strictly unresectable liver metastases, the association of hepatic resection, radiofrequency and chemotherapy, results in 3-year survival rate of $47 \%$. Unfortunately, it doesn't provide survival comparable to radical surgery ${ }^{15}$ but it seems to be better than the obtained with only-chemotherapy ${ }^{14}$, 
${ }^{16}$. Results from EORTC 40004 (FOLFOX vs FOLFOX plus radiofrecuency ablation) are expected.

Percutaneous ethanol injection is less effective in metastatic hepatic colon cancer lesions in comparison to primary hepatocellular carcinomas. There is little evidence to support its use in metastatic colon cancer ${ }^{17}$.

\section{Hepatic resection}

Several significant advances have been made over the last 10 years, that make liver resection a more routine procedure with minimal patient morbidity. The main goal of liver resection is to precisely remove the involved portion of liver with an adequate surgical margin and preserve sufficient hepatic reserve. Intraoperative ultrasonography is the most sensitive modality currently available for detecting otherwise occult liver metastases. Its overall sensitivity is reported to be up to $98 \%{ }^{18}$. The role of laparoscopy before surgical exploration remains to be defined.

Anatomic resection is a superior oncologic resection than wedge or atypical resection. Segmentoriented liver resection represents the virtuosity of hepatic surgery. It is unique in its oncologic efficacy and safety. The technique promotes tumour clearance while preserving uninvolved parenchyma. Preoperative American Society of Anesthesiologists (ASA) classification, presence of steatosis, simultaneous extrahepatic resection and perioperative blood transfusion have been found to be independent predictors for the development of postoperative complications ${ }^{19}$.

5 -year overall survival rate following resection is increasing over the years. At the same time, surgical mortality rate is decreasing. Whereas survival rate examining patients treated from the 60's through the mid 90's was reported to be $33 \%-36 \%{ }^{9}, 20$, most recent reports show figures of $58 \%{ }^{21,22}$. Mortality rates go down from $2,8 \%$ to $0,9 \%$. The overall survival for patients operated on between 1984 and 1992 at John Hopkins Hospital was 31\%, compared to $58 \%$ for the more recent period (1993-1999) $)^{21}$. The mortality reported in more than 1800 consecutive cases from the Memorial Sloan Kettering Cancer Center (1991-2001) decreased from 4\% in the first 5 years to $1,3 \%$ in the last two years ${ }^{23}$. These higher survival and lower mortality rates, probably reflect improvement in perioperative care, multidisciplinary treatment and an appropriately aggressive approach to safe hepatic resection. Patients who undergo liver resection for colorectal metastases and have no recurrence for 4 years thereafter have a cumulative probability that parallels people without cancer ${ }^{1}$.

The two main disadvantages for liver resection are that only a limited number of patients are suitable for surgery and that disease-free survival is ${ }^{10}{ }^{24}$. Fortunately, many presentations of hepatic disease that would previously have been considered unsuitable for surgery are now considered amenable to resection. Strategies designed to increase the proportion of patients to be candidates for complete surgical treatment are emerging, such as neoadjuvant chemotherapy ${ }^{25}$, preoperative portal vein embolization ${ }^{26}$ and 2-stage resection approaches ${ }^{27}$.

An additional issue regarding liver resection after neoadjuvant therapy is how managing the type of resection in patients who had unresectable disease and then responded. Currently the trend is to resect all sites within the liver that contained disease. Actually it should be clarified if it is necessary to resect the volume in which the initial disease resided or it would be enough to take the nidus of residual disease.

\section{Redefining eligibility for resection and prognostic factors}

Historically, only $10 \%$ of patients with liver metastases, had traditionally been considered for resection (1-3 unilobar metastases, $<5 \mathrm{~cm}$ in size, ideally presenting metachronously). The limiting factor is nowadays, whether it is technically possible to remove all the tumour, regardless the number of nodules, as long as no more than $70 \%$ of the liver needs to be removed. The definition of resectability is currently evolving and a number of clinical scores have been devised in order to guide patient selection.

Although surgical resection can cure some patients, the majority will eventually develop recurrent disease. Therefore, several groups have identified some prognostic factors for recurrence. Metachronous detection of colorectal metastases, usually carries a better prognosis than synchronous liver metastases. Regarding primary tumour related factors, positive lymph node status and a disease- 
free interval of less than one year (between resection of the primary tumour and liver metastases) are both associated with poor outcome. Several groups have noted that the site of primary tumour was also an independent predictor of survival. Rougier et al demonstrated that patients whose primary tumours arose in the right colon fared worse than those developed elsewhere in the colon or rectum ${ }^{8}$. However, other investigators have reported a worse survival for patients with rectal tumours ${ }^{24,28}$. High-grade ${ }^{9}$ and stage ${ }^{1,29}$ of primary tumour correlate with poorer survival. With respect to the liver metastases, factors that reflect advanced tumour burden have been shown to predict shorter survival: number of lesions $^{21,29}$, size of largest lesion, bilobar distribution of disease (this is not generally accepted), percent hepatic replacement and weight of resected specimen $^{30}$. While patients with a small tumour size have a better prognosis than those with a large tumour, these ones may still benefit ${ }^{1}$. Though $5 \mathrm{~cm}$ was the historical threshold, more updated reviews have shown that tumour size exceeding $10 \mathrm{~cm}$ has a poorer prognosis ${ }^{25}$. No long-term survivors have been reported when more than $50 \%$ of the liver was replaced by metastatic colorectal cancer at the time of the surgery ${ }^{9}$. Elevation in preoperative serum carcinoembryonic antigen (CEA) levels is consistently associated with poorer outcome ${ }^{20,21,29-31}$. Ca 19.9, less often studied, could also be one of most important prognostic factors ${ }^{25}$. Alkaline phosphatase and albumin were independent prognosticator in a recent study ${ }^{29}$. Regarding technical factors, a positive or close resection margin are predictive of poor outcome $^{21,32}$. Anatomical resections have a significant survival benefit over lesser procedures in some analysis $^{9}$ and the non-curative pattern of hepatectomy is identified as a prognostic factor ${ }^{25}$. Though all tumours should be removed with an adequate margin, in some situations, such as contact with the contralateral portal triad sheath, the resection margin may be zero, if a macroscopic R0 resection can be achieved with potentially curative intent. Of course, resection must be achieved without cutting across the tumour ( $\mathrm{R} 1$ resection), and a true positive margin remains a contraindication to curative surgery $^{1}$. The optimal width of the negative surgical margin remains controversial.

Adam and co-workers have recently updated its experience with initially considered unresectable colorectal liver metastases after neoadjuvant chemotherapy. They have found four preoperative risk factors that could help to select the patients most likely to benefit from this strategy. Rectal primary, three or more metastases, maximum tumour size of $10 \mathrm{~cm}$ and $\mathrm{Ca} 19.9>100 \mathrm{UI} / \mathrm{L}$ have been reported as preoperative factors associated with decreased survival $^{25}$. Extrahepatic disease had no significant impact on survival except metastatic lymph nodes of the hepatic pedicle.

Possible contraindications for surgery: Resection may be considered in all patients fit enough to tolerate general anaesthesia. Absolute contraindications for resection of colorectal liver metastases have not been clarified, but most would agree that patients should not be offered resection if they have uncontrolled primary disease or such widespread intrahepatic involvement that the residual liver function after resection would be inadequate. Most authorities would agree that presently it would be safe to resect up to $70 \%$ of a healthy liver. One factor that theorically precludes potentially curative liver resection is the involvement of lymph nodes at the hepatic hilum. However, some studies suggest benefit from radical excision of nodes in the region of the hepatic pedicle $^{31}$. Though the presence of extrahepatic disease significantly reduces the likelihood of long-term survival, there are some instances where patients with extrahepatic disease can be considered for resection with potentially curative intent. These cases include direct diaphragmatic invasion, resectable local colorectal recurrence and resectable lung metastases that are readily resectable and few in number ${ }^{33}$. Patients with adrenal gland metastases may survive for more than 5 years ${ }^{1}$.

Relative contraindications include situations where resections are not easily performed such as those involving the caudate lobe or tumours invading the inferior vena cava or the portal vein confluence.

\section{Neoadjuvant chemotherapy}

Neoadjuvant therapy refers to the use of chemotherapy in patients who present localized or locally advanced cancer. However, this term can also be used for referring to some treatments administered before what is considered a curative treatment such as liver disease secondary to colon cancer. In this 
setting, neoadjuvant therapy refers to "primary induction treatment for advanced disease followed (if possible) by surgery with curative intention".

The feature of administering chemotherapy before surgery is the preservation of the tumour mass as a biologic marker of chemosensitivity of the drugs. A hypothetical advantage would be accessing tissues while they are fully oxygenated and vascularized, diminishing micrometastases or circulating tumour cells ${ }^{34}$. As we mentioned before, chemotherapy itself could spare ineffective surgical treatment ${ }^{13}$. The question remains whether the response to chemotherapy simply identifies patients with a favourable prognosis or could modify the course of the disease.

What we can learn from other diseases with regards to neoadjuvant treatment is that it has allowed the sparing of some organs (such as bladder, larynx, anal sphincter or other). It also decreases the rate of post-operative complications in rectal cancer. And finally, in lung cancer, the neoadjuvant treatment impacts the survival at some stages.

The introduction of new chemotherapeutic regimens, may convert up to one third of non- resectable patients to resectability with curative intent (see Table I) ${ }^{35-39}$. A recent report reviews 1439 consecutive unresectable cases treated with surgery after neoadjuvant chemotherapy. The mortality rate was

\section{TABLE I}

\section{Resection rates after chemotherapy in initially inoperable patients}

\begin{tabular}{|c|c|c|}
\hline Author & Patients & Surgery Rate (RO) \\
\hline \multicolumn{3}{|c|}{ Oxaliplatin-based } \\
\hline Alberts $2003^{35}$ & 42 & $36 \%$ \\
\hline Adam $2004^{27}$ & 1439 & $12.5 \%$ \\
\hline Tournigand $2004^{45}$ & 111 & $22 \%$ \\
\hline Delaunoit $2005^{36}$ & 267 & $4 \%$ \\
\hline \multicolumn{3}{|c|}{ Irinotecan-based } \\
\hline Ducreux $2003^{37}$ & 55 & $31 \%$ \\
\hline Pozzo $2004^{41}$ & 40 & $33 \%$ \\
\hline Tournigand $2004^{45}$ & 109 & $9 \%$ \\
\hline Delaunoit $2005^{36}$ & 264 & $1 \%$ \\
\hline \multicolumn{3}{|c|}{ Oxiri-based } \\
\hline Falcone $2004^{38}$ & 74 & $26 \%$ \\
\hline Quenet $2004^{39}$ & 34 & $37.5 \%$ \\
\hline Delaunoit $2005^{36}$ & 265 & $4 \%$ \\
\hline
\end{tabular}

$0,7 \%, 5$-year disease free and overall survival of $22 \%$ and $33 \%$ respectively and 10-year disease free and overall survival of 17 and $23 \%$. This report offers a considerable support to both feasibility and results in initially unresectable patients treated with neoadjuvant chemotherapy. Although several studies demonstrate the utility of chemotherapy in rendering unresectable liver metastases resectable, full clinical evidence is missing, since no randomized trials have been completed with this purpose.

It is a subject of debate when to operate (after neoadjuvant therapy). Some groups suggest that surgery must be performed as soon as resectability is technically possible. The date of operation should be chosen to avoid a long interval between the last chemotherapy and surgery.

The main criticism for most reported as neoadjuvant studies, is that they do not evaluate prospectively the outcomes related to resectability. The criteria for non-resectability differed between the studies and were poorly defined. Poor prognosis does not imply non-resectability, and some surgeons could be prone to classify as non-resectable a poor prognosis patient, hoping that neoadjuvant therapy could change some prognosis factors. And it does change them. What is not so clear is if either the decrease of the number of nodules or the decrease of the size of nodules actually translate into a better survival. This question could only be answered through a randomized clinical trial which is unlikely to be launched.

When designing clinical trials for neoadjuvant therapies, the inclusion of appropriate surrogate endpoints (obviously final endpoint is overall survival) should be kept in mind. It has been clearly demonstrated that new agents improve survival, but improvement of response rates is not less important in this setting since a good shrinkage is necessary to allow the further surgery. The objective response rate has been recently associated with the resection rate of metastases ${ }^{40}$. When tumour size is the non-resectability criterion, chemotherapy is the best option. ${ }^{41}$ In patients with synchronous metastases, the response to neoadjuvant chemotherapy may even be a prognostic indicator of survival and might assist in the selection of patients ${ }^{42}$. Some additional endpoints for trials in the neoadjuvant setting would be tumour shrinkage, patients eventually resected with curative intention, $\mathrm{R} 0$ resection rates, rates of com- 
plete response, tumour necrosis in the pathological specimen, etc.

The choice of upfront therapy when considering the possibility of being a neoadjuvant therapy is critical. The most relevant indicator of the effectiveness of chemotherapy is the rate of complete response. The main requirement for drugs or combinations to be used in the neoadjuvant setting is to have documented evidence for its clinical efficacy in the advanced disease setting. The recent advances in treatment of advanced colorectal cancer have brought significant improvements in overall response rates and survival, yet have not translated into an actual cure for the disease. The reason is that the complete response rate for these regimens has been lower than $10 \%$ and no patient with advanced cancer has ever been cured without first achieving a complete remission. A new (fortunate but infrequent) challenge is the management of the complete responders ${ }^{42}$. The best approach to these infrequent situations has not been defined yet, and a case-bycase decision has to be made.

Prospective randomized studies are now underway in an attempt to define the utility of adjuvant therapy in the treatment of liver-only metastases from colorectal cancer. A randomized phase III study (40983) of the European Organization for Research and Treatment of Cancer study has tested the impact of preoperative and postoperative chemotherapy in resectable liver metastases. Surgical morbidity and mortality $(0,9$ and $1,6 \%$ in the chemotherapy and only-surgery arms respectively) were low. Results on survival are still pending. This trial will generate some information with regards to the role of chemotherapy but we will have no information regarding the right moment to administer chemotherapy (before or after surgery). One trial, N014A, is evaluating the surgical resectability rate after cetuximab plus oxaliplatin fluoracil and leucovorin, of patients with advanced colorectal cancer confined to the liver, initially considered suboptimal for resection.

\section{Systemic treatment for colon cancer}

The antimetabolite $5 \mathrm{FU}$ was until a decade ago the only first line chemotherapeutic option for patients with advanced colorectal cancer. In spite of extensive efforts to improve response by modifying schedules, doses and modulators, median survival did not exceed 12 months. The modern era of colon cancer chemotherapy began in the mid-1990s, when the two novel chemotherapeutic agents irinotecan and oxaliplatin were found to have significant activity. Since then, the treatment of advanced colon cancer has evolved considerably ${ }^{44}$. Where there had previously been only one effective agent available for palliation, namely 5-FU, there are now a number of effective agents. During the past decade the FDA and the EMEA have approved five new drugs for metastatic colorectal cancer.

Though survival has been the main concern regarding adjuvant and metastatic treatments (at least for Health Authorities approvals), response rates and disease free survival could be more relevant to neoadjuvant therapy. As we mentioned before, the relationship between response and resectability rate has been well established ${ }^{40,41}$ and would support the strategy of using the most active regimens in potential curable patients. Pozzo et al showed that only $18 \%$ of patients with stable disease after neoadjuvant chemotherapy for non-resectable patients underwent surgery ${ }^{41}$.

In Europe, where the infusional 5-FU regimens were developed, these drugs have such been combined. The rate of objective responses is now in the range of $40-50 \%$. Response rates obtained with FOLFOX and FOLFIRI are considered to be equivalent $^{45,46}$. Though more patients receiving FOLFOX as their first-line were able to go on to have resection ${ }^{45}$. Main differences are found in the toxicity profile. Although the optimal neoadjuvant regimen has yet to be determined most evidence suggest that infusional FU/LV with oxaliplatin or irinotecan are the most effective for this purpose. Table II shows the most active regimens (only regimens tested in phase III are mentioned $)^{47-53}$.

The two main reasons for the use of infusional regimens are a more favourable toxicity profile and prolonged thymidilate synthase inhibition. ${ }^{54}$ Infusional administration of $5 \mathrm{FU}$ is less toxic, overshadowing issues related to the added cost, inconvenience and chance of catheter-related complications. Median number of cycles before surgery is about 10 , and current trends in some groups is to perform surgery as soon as it is technically feasible $e^{25}$. Therefore neurotoxicity does not seem to be a major concern in the neoadjuvant setting. Alopecia may be more 
TABLE II

The efficacy of most active (more than $40 \% \mathrm{RR}$ ) chemotherapeutic regimens tested in randomized trials

\begin{tabular}{|c|c|c|c|c|}
\hline Regimen & Study & Number pts & $R R$ & Median PFS(months) \\
\hline \multicolumn{5}{|c|}{ Irinotecan first line } \\
\hline CPT+infFU LV & Douillard $2000^{47}$ & 199 & $41 \%$ & $6.7 \mathrm{mo}$ (TTP) \\
\hline $\mathrm{CPT}+\mathrm{AIO} \mathrm{FU}$ & Koehne $2003^{48}$ & 214 & $54.2 \%$ & $8.5 \mathrm{mo}$ \\
\hline $\mathrm{CPT}+\mathrm{AIO} 5 \mathrm{FU}$ & Heinemann $2004^{49}$ & 106 & $45 \%$ & Not reported \\
\hline FOLFIRI & Tournigand $2004^{45}$ & 109 & $56 \%$ & $14.2 \mathrm{mo}$ \\
\hline \multicolumn{5}{|c|}{ Oxaliplatin first line } \\
\hline $\begin{array}{l}\text { Oxal/FU/LV } \\
\text { (chronomodulated) }\end{array}$ & Giachetti $2000^{50}$ & 100 & $53 \%$ & $6.1 \mathrm{mo}$ \\
\hline FOLFOX & De Gramont $2000^{51}$ & 210 & $50.7 \%$ & $9.0 \mathrm{mo}$ \\
\hline FOLFOX & Goldberg $2004^{52}$ & 267 & $45 \%$ & $8.7 \mathrm{mo}$ \\
\hline FUFOX & Grothey $2002^{55}$ & 118 & $48.3 \%$ & $7.9 \mathrm{mo}$ \\
\hline FOLFOX & Tournigand $2004^{45}$ & 111 & $54 \%$ & $10.9 \mathrm{mo}$ \\
\hline \multicolumn{5}{|c|}{ Bevacizumab first line } \\
\hline IFL/ Bevacizumab & Hurwitz $2004^{59}$ & 402 & $44.8 \%$ & $10.6 \mathrm{mo}$ \\
\hline FOLFOX6/Bevacizum & Hochster $2005^{66}$ & 71 & $62 \%$ & 8.7 (TTP) \\
\hline \multicolumn{5}{|c|}{ CPT11 and oxaliplatin } \\
\hline IROX & Heinemann $2004^{49}$ & 109 & $53 \%$ & Not reported \\
\hline Oxal/CPT/5FU/fol & Souglakos $2004^{53}$ & 102 & $45 \%$ & $8.9 \mathrm{mo}$ \\
\hline
\end{tabular}

frequently with irinotecan. However if irinotecan is used weekly in doses below $100 \mathrm{mg} / \mathrm{m}^{2}$ less than $10 \%$ of patients will have alopecia.

It has been suggested that sequence of drugs is not as important as the availability of all of them ${ }^{55}$. A paper recently published by Dr Poston criticizes very harshly the policy of the UK National Institute for Clinical Excellence, stating that many British patients have been denied an effective treatment as a consequence of its 2002 guidance (recommending the use of 5FU-folinic as first line therapy) ${ }^{56}$. We physicians, must do our best in order to achieve the best therapies to be approved as soon as possible. But we must also keep in mind that doubling the median survival in these patients is accompanied by a 340-fold increase in drug costs ${ }^{57,58}$. And drugs by themselves remain a palliative option, since there is no evidence that the new therapies increase cure rates. We must look again at multidisciplinary treatments.

The new targeted agents directed against EGF receptor or VEGF are increasing the efficacy of chemotherapy. Whereas a survival benefit has been seen with bevacizumab in both the first- line with
IFL (irinotecan/5FU, leucovorin) ${ }^{59}$ and second-line settings (FOLFOX), the larger benefit in first line suggests that this agent should now also be considered a standard first line option. Cetuximab when added to patients with irinotecan resistance not only improved the rate of objective response but also prolonged the progression-free survival ${ }^{60}$. Promising data have also been reported when bevacizumab was added to a combination of irinotecan and cetuximab in irinotecan-refractory patients ${ }^{61}$. It should be mentioned that addition of bevacizumab to $5 \mathrm{FU} / \mathrm{fol}$ seems to be as effective in terms of response rates as IFL (irinotecan /5FU/fol) ${ }^{62}$. Bevacizumab increases overall survival by $30 \%$. We could expect a parallel advantage regarding response rates or tumour shrinkage ${ }^{63}$.

These new agents will be incorporated into neoadjuvant trials. However, it is essential to define its role in well designed clinical trials, that should also explore potential adverse events related to these new drugs. Bevacizumab could have a deleterious effect in wound healing, as well as bleeding complications, bowel perforations, thromboembolic events etc $^{59}$. On the other hand, as we said before, objecti- 
TABLE III

Gene expression and polymorphisms: influence on response and toxicity

\begin{tabular}{|lll|}
\hline $5 F U$ & Irinotecan & Oxaliplatin \\
\hline Thymidilate synthase & P450 3A4 & XPD gene \\
Dihydropirimidine Hydrogenase & ATP-binding cassette reporters & Excision repair enzyme XRCC1, ERCC2 \\
Thymidine Phosphorilase & Carboxylesterase & GSH-dependent enzymes \\
& UGT1A1 & EGFR \\
\hline
\end{tabular}

ves to be achieved with new therapies in every setting must be properly defined.

So far the most appealing results reported in first line, with regards to response rate, included cetuximab combined with FOLFOX $(81 \%)^{64}$, cetuximab combined with FOLFIRI-AIO $(74 \%)^{65}$, bevacizumab combined with FOLFOX6 $(62 \%)^{66}$ and oxaliplatin combined with irinotecan $(70 \%)^{67}$ all in phase II trials. FOLFOX plus cetuximab and FOLFIRIAIO plus cetuximab had the same figures for resectability rates: $21 \%$. FOLFOXIRI rendered $26 \% \mathrm{R} 0$ resected patients. Of note, regimens including cetuximab were only administered to EGFR positive patients, while some EGFR negative patients could benefit from this treatment ${ }^{68}$. Should these results be confirmed in phase III trials, these combinations could become a good option as a neoadjuvant therapy.

$\mathrm{PTK} / \mathrm{ZK}$ is an orally active small molecule that blocks both angiogenesis and lymphangiogenesis by inhibiting tyrosine kinase signaling. This drug could have a positive effect when added to FOLFOX, mainly in patients with high LDH. This fact can be interesting since most adverse prognostic factors before surgery are related to tumoral volume ${ }^{69}$. Other small molecule VEGF inhibitors, including SU11248 and Bay 439006 are also in clinical development.

Data are now accumulating about the efficacy of second -line therapy. We must be prepared to face liver relapses after adjuvant treatment with FOLFOX, that was recently approved by the EMEA in node-positive colon cancer adjuvant therapy. Specific clinical trials designed for these patients would help to clarify the best option. The assumption that 5 FU would be beneficial throughout treatment should also be tested in clinical trials.

Other drugs such as pemetrexed (ALIMTA), epothilones (microtubule-stabilizing drugs), edote- carin (non-camptothecin topoisomerase I inhibitor) and tezacitabine (nucleoside analog to gemcitabine) could be added to the colorectal armamentarium in the next years. But it is too early to evaluate its possible impact on the neoadjuvant setting.

Incremental improvements in survival, symptom palliation and quality of life have been achieved with the new therapies. Conventional chemotherapy has moved prognosis for patients with metastatic colorectal cancer from 12 months to 20 months and beyond. The emergence of biologic therapies, has expanded the options for treatment. The number of potential combinations has grown such that the complexity of delivering care in colorectal cancer is far greater than in the past.

\section{Prediction of chemotherapy response}

Our decision to recommend a specific treatment is usually based on tumour and patient-related factors known to influence treatment outcome (efficacy and toxicity). However in many cases all these factors are not sufficiently predictive with respect to treatment response and side effects. We need more precise tools to predict individual response and possible toxicities of drug therapy. The pharmacogenomic profile of individual patients is crucial in order to predict efficacy and toxicity. More information is urgently needed to allow individualization of treatment options for patients (See Table III).

\section{Hepatic arterial chemotherapy (HAC)}

The dual blood supply of the liver and the access to the hepatic artery, make it an appealing route for the delivery of therapy directly to the liver. The rationale for HAC is that liver metastases are perfused almost exclusively by the hepatic artery, whereas normal hepatocytes derive most of their blood 
supply from the portal vein as well and little from the hepatic artery. The chemotherapeutic agents are delivered via implantable pumps or subcutaneous port. FUDR is the best drug to use for regional therapy because 94 to $99 \%$ of FUDR is extracted during the first pass compared to 19 to $55 \%$ of 5-FU. Response rates range between 40 and $60 \%$. HAC is superior to intravenous chemotherapy in terms of response rate but not in terms of survival ${ }^{70}$. Some groups incorporate this strategy as neoadjuvant therapy to allow some patients to undergo liver resection $^{71}$. There is a risk of extrahepatic progression, and sometimes, both intrahepatic and intravenous infusion are alternatively administered. A recent paper reports an amazing $90 \%$ response rate in pretreated patients using this strategy ${ }^{72}$.

Progress in technical procedures (percutaneously placed catheters), progress in treatment modalities (new drugs such as oxaliplatin or angiogenesis inhibitors) as well as in indications (in chemo-resistant patients) mark the future directions of this technique.

\section{Chemotherapy and liver toxicity}

Chemotherapy can result in liver toxicity, particularly when administered for prolonged duration. Steatosis denotes the accumulation of fat in the liver and is commonly associated with obesity. Use of oxaliplatin has been recently associated with development of hepatic sinusoidal obstruction and hepatic steatosis. For steatohepatitis to occur, a "second hit" seems to be required and some drugs (as well as parenteral nutrition or other) can act as secondhit. In fact, oxaliplatin and irinotecan can be associated with steatohepatitis. Presence of esteatohepatitis is associated with increased hepatic failure after major hepatic resection being more likely to occur in the obese. This liver steatohepatitis can affect hepatic reserve, decreasing rather than increasing resectability and might make the liver resection riskier. ${ }^{73}$ In this situation, portal vein embolization could be recommended to induce hypertrophy of the uninvolved liver.

What type of chemotherapy is associated with increased hepatotoxicity is not clear. Neither it is the duration of the treatment. We have even less information on newer biologic agents such cetuximab or bevacizumab.

\section{Adjuvant therapy of colon liver metastases}

Approximately $70 \%$ of patients who undergo hepatic resection experience recurrent metastases within 2 years and approximately one-half recur in the liver. While it would be desirable to perform a clinical trial to test treatment strategies and to know the exact role of adjuvant chemotherapy, the design for such a trial poses logistic and ethical difficulties.

A Memorial Sloan Kettering study of chemotherapy following liver resection compared standard systemic chemotherapy (based on 5FU) with a regimen consisting of systemic 5FU/leucovorin alternating with hepatically infused FUDR. The regimen incorporating hepatic arterial infusion was more effective in terms of improving overall survival ${ }^{74}$. Of note, the median follow-up was only 33 months and the study was limited to patients with fewer than four metastases.

The question of regional versus systemic adjuvant chemotherapy following hepatic metastasectomy is being evaluated by two upcoming trials conducted by the NSABP and the ACSOG in the US.

\section{Re-resection of metastases}

After surgery for colon liver metastases, relapse will occur in $60-70 \%$ of patients ${ }^{75}$ occurring on the opposite side of the liver in more than a third of cases. The majority of patients who develop recurrence following hepatic resection of colorectal metastases relapse within 2 years of surgery. Therefore aggressive surveillance may improve the early detection of recurrent disease. Approximately $20 \%$ of these patients have liver-only recurrence and hence may be suitable for resection. It is well established that even serial hepatectomy for recurrent colorectal metastasis is feasible if the performance status of the patient supports a series of operations. As might be expected, a longer time to recurrence was predictive of a more favourable outcome ${ }^{76}$.

\author{
Correspondence: \\ Dra. A. Ruiz-Casado \\ Department of Medical Oncology \\ Hospital de Fuenlabrada \\ Camino del Molino, $\mathrm{s} / \mathrm{n}$ \\ E-28942 Fuenlabrada (Madrid) \\ E-mail address: aruiz.hflr@salud.madrid.org
}




\section{References}

1. Poston G. Surgical strategies for colorectal liver metastases. Surg Oncol 2004; 13: 125-126

2. Skandalakis JE, Skandalakis LJ, Skandalakis PN and Mirilas P. Hepatic surgical anatomy. Surg Clin N Am 2004; 84: 413-435

3. Terminology Committee of the International Hepato-Pancreato-Biliary Association. Brisbane 2000. Terminology of liver anatomy \& resections. Hepatobiliary Pancreat Surg 2000; 2:333-339

4. Jessup JM, Mc Ginnis LS, Steele GD Jr et al. The National Cancer Data Base. Report on colon cancer. Cancer 1996; 78: 918-926

5. Borner MM. Neoadjuvant chemotherapy for unresectable liver metastases of colorectal cancer- too good to be true? Ann Oncol 1999; 10: 623-6

6. Adson mA, van Heerden JA, Adson MH et al. Resection of hepatic metastases from colorectal cancer. Arch Surg 1984; 119: 647-651

7. Hugh TJ, Kinsella AR, Poston GJ. Management strategies for colorectal liver metastases. 1. Surgical Oncology 1997; 6(1): 19-30

8. Rougier P, Milan C, Lazorthes F et al. Prospective study of prognostic factors in patients with unresected hepatic metastases from colorectal cancer. Br J Surg 1995, 82: 1397

9. Scheele J, Stang R, Altendorf -Hofmann A, Paul M. Resection of colorectal liver metastases. World J Surg 1995; 19: $59-71$

10. Valls C, Andia E, Sanchez A, et al. Hepatic metastases from colorectal cancer: preoperative detection and assessment of resectability with helical CT. Radiology 2001; 218:55

11. Ruers TJ, Langenhoff BS, Neeleman N et al. Value of positron emission tomography with [F-18] fluorodeoxiglucose in patients with colorectal liver metastases: a prospective study. J Clin Oncol 2002; 20: 388

12. Treating liver metastases in colorectal cancer. An expert interview with Michael Choti, MD. Available from http://www.medscape.com/viewarticle/506325

13. Adam R, Pascal G, Castaing D. Tumor progression while on chemotherapy. A contraindication to liver resection for multiple colorectal metastases. Ann Surg 2004; 240: 1052-1064

14. Berber E, Pelley R and Siperstein AE et al. Predictors of survival alter radiofrequency termal ablation of colorectal cancer metastases to the liver: A prospective study. J Clin Oncol 2005; 23: 1358-1364

15. Abdalla EK, Vauthey JN, Ellis LM et al. Recurrence and outcomes following hepatic resection, radiofrequency ablation, and combined resection/ablation for colorectal liver metastases. Ann Surg 2004; 239: 818-827

16. Elias D, Baton O, Sideris L et al. Hepatectomy plus intraoperative radiofrequency ablation and chemotherapy to treat technically unresectable multiple colorectal liver metastases. J Surg Oncol 2005; 90: 36-42
17. Ruan DT and Warren RS. Liver-directed therapies in colorectal cancer. Semin Oncol 2005; 32: 85-94

18. Conlon R, Jacobs M, Dasgupta D et al. The value of intraoperative ultrasound during hepatic resection compared with improved preoperative magnetic resonante imaging. Eur J Ultrasound 2003; 16: 211-216

19. Redai I, Emond J, Brendjens T. Anesthetic considerations during liver surgery. Surg Clin N Am 2004; 401-411

20. Fong Y, Fortner J, Sun RL et al. Clinical score for predicting recurrence after hepatic resection for metastatic colorectal cancer. Ann Surg 1999; 230:309-318

21. Choti MA, Sitzman JV, Tiburi MF et al. Trends in long term survival following liver resection for hepatic colorectal metastases. Ann Surg 2002; 235: 759-765

22. Abdalla EK, Vauthey JN, Ellis LM et al. Recurrence and outcomes following hepatic resection, radiofrequency ablation, and combined resection/ablation for colorectal liver metastases. Ann Surg 2004; 239: 818-827

23. Jarnagin WR, Gonen M, Fong Y, et al. Improvement in perioperative outcome alter hepatic resection: análisis of 1803 cases over the past decade. Ann Surg 2002; 236: 397-406

24. Alexander HR, Kemeny NE and Lawrence TS. Metastatic cancer to the liver. In: De Vita VT, Hellman S, Rosenberg SA. Philadelphia- New York: Lippincot-Raven; 2005. p 2352-2367

25. Adam R, Delvart V, Pascal G et al. Rescue surgery for unresectable colorectal liver metastases downstaged by chemotherapy. A model to predict long-term survival. Ann Surg 2004; 240: 644-658

26. Abadía EK, Hicks ME Vauthey JN. Portal vein embolization: rationale, technique and future prospects. Br J Surg 2001; 88: 165-175

27. Adam R, Laurent A, Azoulay D et al. Two-stage hepatectomy: a planned strategy to treat irresectable liver tumors. Ann Surg 2000; 88: 165-175

28. Jatzko GR, Lisborg PH, Stettner HM et al. Hepatic resection for metastases from colorectal carcinoma- a survival analysis. Eur J Cancer 1995; 31A: 41-6

29. Schindl M, Wigmore SJ, Currie E, Laengle F and Garden J. Prognostic scoring in colorectal cancer liver metastases. Arch Surg 2005; 140: 183-189

30. Bakalakos EA, Kim JA, Young DC, Martin Ew Jr. Determinants of survival following hepatic resection for metastatic colorectal cancer. World J Surg 1998; 22: 339-404

31. Nordlinger B, Guiguet M, Vaillant JC et al. Surgical resection of colorectal carcinoma metastases to the liver. A prognostic scoring system to improve case selection based on 1568 patients. Cancer 1996; 77: 1254-62

32. Cady B, Jenkins RL, Steele GD Jr et al. Surgical margin in hepatic resection for colorectal metastasis. A critical and improveable determinant of outcome. Ann Surg 1998; 227: 566-71

33. Vogelsang H, Haas S, Hierholzer et al. Factors influencing survival after resection of pulmonary metastases from colorectal cancer. Br J Surg 2004;91: 1066-71 
34. Venook AP Colorectal metastases confined to the liver: a unique opportunity? Semin Oncol 2003; 30 (suppl 15): 34-39

35. Alberts SR, Donohue JH, Mahoney WL et al. Liver resection after 5-Fluoracil, leucovorin and oxaliplatin for patients with metastatic colorectal cancer limited to the liver.: a North Central Cancer Treatment Group phase II study. Proc Am Soc Clin Oncol 2003; 22: 263 (abstract 1053)

36. Delaunoit TP, Krook J, Sargent E et al. Chemotherapyallowed resection of metastatic colorectal cancer: A cooperative group experience. Proc Gastrointest Symp 2004: abstr 196

37. Ducreux M, Raoul JL, Marti P et al. Enhanced efficacy in patients receiving irinotecan high-dose $260 \mathrm{mg} / \mathrm{m} 2$ with 5FU/FA (LV5FU2 or LV5FUS) in first line metastatic colorectal cancer. Updated results of a phase II study. Proc 14th Int Congr Anti-Cancer Treatment (ICACT) 2003; 203-204 (abstract)

38. Falcone A, Masi G, Cupini S et al. Surgical resection of metastases alter biweekly chemotherapy with irinotecan, oxaliplatin and 5 fluoracil/ leucovorin (FOLFOXIRI) in initially unresectable metastatic colorectal cancer. Proc Am Soc Clin Oncol 2003, 22: 263 (abstract 1053)

39. Quenet F, Nordlinger B, Rivoire M et al. Resection of previously unresectable liver metastases from colorectal cancer after chemotherapy with CPT11/ L-OHP/LV5FU (Folfirinox): A prospective phase II trial. Proc Am Soc Clin Oncol 2004, 23: 273 (abstract 3613)

40. Folprecht G, Grothey A, Alberts S, Raab HR and Köhne $\mathrm{CH}$. Neoadjuvant treatment of unresectable colorectal liver metastases: correlation between response rates and resection rates. Ann Oncol 2005; 16(8): 1311-19

41. Pozzo C, Basso M, Cassano A et al. Neoadjuvant treatment of unresectable liver disease with irinotecan and 5fluoracil plus folinic acid in colorectal cancer patients. Ann Oncol 2004; 15: 933-939

42. Allen PJ, Kemeny N, Jarnagin W, DeMatteo R, Blumgart $\mathrm{L}$ and Fong Y. Importance of response to neoadjuvant chemotherapy in patients undergoing resection of synchronous colorectal liver metastases. J Gastroint Surg 2003; 7: 109117

43. Shrag D, Weiser M, Schattner M, Shia J, and Akhurst T. An increasingly common challenge: management of the complete responder with multifocal metastatic colorectal cancer. J Clin Oncol 2005; 23: 1799-1802

44. O'Neil BH and Goldberg RM Chemotherapy for advanced colorectal cancer: Let's not forget how we got here (until we really can). Semin Oncol 2005; 32: 35-4 2

45. Tournigand C, Andre T, Achille E et al. FOLFIRI followed by FOLFOX6 or the reverse sequence in advanced colorectal cancer: a randomized GERCOR study. J Clin Oncol 2004; 22: 229-37

46. Colucci G, Gebbia V, Paoletti G et al. Phase III randomized trial of FOLFIRI versus FOLFOX4 in the treatment of advanced colorectal cancer: a multicenter study of the Gruppo Oncologico Dell' Italia Meridionale. J Clin Oncol 2005; 23(22): 4866-75
47. Douillard JY, Cunningham D, Roth AD et al. Irinotecan combined with fluoracil compared with fluoracil alone as first-line treatment for metastatic colorectal cancer: A multicenter randomised trial. Lancet 2000; 355: 1041-1047

48. Kohne $\mathrm{CH}$, Van Cutsem E, Wils JA et al. Irinotecan improves the activity of the AIO regimen in metastatic colorectal cancer: Results of EORTC GI Group study 40986. Proc Am Soc Clin Oncol 2003; 22: 254 (abstract 1018)

49. Heinemann V, Schalhorn A, Fischer von Weikerstahl et al. Phase III trial: Irinotecan plus oxaliplatin versus irinotecan plus 5 fluoracil/folinic acid for first line treatment of colorectal cancer. Proc Gastrointest Cancer Symp 2004; abstract 274

50. Giacchetti S, Perpoint B, Zidani R et al. Phase III multicenter randomized trial of oxaliplatin added to chronomodulated Fluoracil-leucovorin as fist-line treatment of metastatic colorectal cancer. J Clin Oncol 2000; 18: 136-147

51. De Gramont A, Figer A, Seymour M et al. Leucovorin and fluoracil with or without oxaliplatin as first-line treatment in advanced colorectal cancer. J Clin Oncol 2000; 18: 2938-2947

52. Goldberg RM, Sargent DJ, Morton RF et al. A randomized controlled trial of fluoracil plus leucovorin, irinotecan and oxaliplatin combinations in patients with previously untreated metastatic colorectal cancer. J Clin Oncol 2004; 22: 23-30

53. Souglakos J, Ziras N, Polyzos A et al. Oxaliplatin combined with irinotecan, leucovorin and fluoracil compared with irinotecan, leucovorin and fluoracil as first-line treatment for metastatic colorectal cancer: Preliminary results of a multicenter randomized phase III trial. J Clin Oncol 2004, 22 (14S): 3532

54. Meta-analysis Group in Cancer. Efficacy of intravenous continuous infusion of fluoracil compared with bolus administration in advanced colorectal cancer. J Clin Oncol 1999; 16: 301-308

55. Grothey A, Sargent D, Goldberg RM et al. Survival of patients with advanced colorectal cancer improves with the availability of fluoracil-leucovorin, irinotecan and oxaliplatin in the course of treatment. J Clin Oncol 2004; 22: 1209-1214

56. Poston GJ. The use of irinotecan and oxaliplatin in the treatment of advanced colorectal cancer. Eur J Surg Oncol 2005; 31: 325-330

57. Schrag D. The price tag on progress. Chemotherapy for colorectal cancer. N Eng J Med 2004; 351: 317

58. Kelly $\mathrm{H}$ and Goldberg RM. Systemic therapy for metastatic colorectal cancer: current options, current evidence. J Clin Oncol 2005; 23: 4553-4560

59. Hurwitz H, Fehrenbacher L, Novotny et al. Bevacizumab plus Irinotecan, Fluorouracil and leucovorin for metastatic colorectal cancer. N Engl J Med 2004; 350: 2335-42

60. Cunningham D, Humblet Y, Siena S et al. Cetuximab monotherapy and cetuximab plus irinotecan in irinotecan-refractory metastatic colorectal cancer. N Eng J Med 2004; 351: $337-345$ 
61. Saltz LB, Lenz HJ, Hochster H et al. Randomized phase II trial of cetuximab/bevacizumab/irinotecan (CBI) versus cetuximab/bevacizumab (CB) in irinotecan-refractory colorectal cancer. Proc Am Soc Clin Oncol 2005; 23:248s (abstract 3508)

62. Hurwitz HI, Fehrenbacher L, Hainsworth JD et al. Bevacizumab in combination with fluoracil and leucovorin: an active regimen for first line metastatic colorectal cancer. J Clin Oncol 2005; 23: 3502-3508

63. Kabbinavar FF, Schulz J, McCleod M et al. Addition of bevacizumab to bolus fluoracil and leucovorin in first-line metastatic colorectal cancer: results of a randomized phase II trial. J Clin Oncol 2005; 23: 3697-3705

64. Díaz-Rubio E, Tabernero J, van Cutsem E, et al. Cetuximab in combination with oxaliplatin/ 5-fluoracil/ folinic acid (FOLFOX4) in the first-line treatment of patients with epidermal growth factor receptor (EGFR)-expressing metastatic colorectal cancer Preliminary results: an international phase II study. Proc Am Soc Clin Oncol 2005; 23:254s (abstract 3535)

65. Folprecht G, Lutz M, Schöffski P et al. Cetuximab/ Irinotecan/ High dose 5-fluoracil/ leucovorin in the first-line therapy of metastatic colorectal cancer. Proc Gastrointest Cancer Symp (ASCO/AGA/ASTRO/SSO) 2004; 1(abstr 283)

66. Hochster HS, Welles L, Hart L et al. Bevacizumab with oxaliplatin-based chemotherapy in the first-line therapy of metastatic colorecatl cancer (mCRC): preliminary results of the randomized "TREE-2" trial. Proc Gastrointest Cancer Symp et al, 2005 (abstract 241).

67. Falcone A, Masi G, Allegrini G et al. Biweekly chemotherapy with oxaliplatin, irinotecan, infusional fluoracil, and leucovorin: a pilot study in patients with metastatic colorectal cancer. J Clin Oncol; 2002: 4006-4014

68. Chung KY, Shia J, Kemeny NE et al. Cetuximab shows activity in colorectal cancer patients with tumors that do not express the epidermal growth factor receptor by immunohistochemistry. J Clin Oncol 2005; 23: 1803-1810

69. Hecht JR, Trarbach T, Jaeger E et al. A randomized, double blind, placebo controlled, phase III study in patients with metastatic adenocarcinoma of the colon or rectum receiving first line chemotherapy with oxaliplatin/ 5Fluoracil/leucovorin and PTK787/ZK 222584 or placebo (CONFIRM 1). Proceedings of the 41st ASCO annual meeting; 2005 May 13-17; Orlando USA. J Clin Oncol 2005; 23 (16S) part II: 1090S

70. Elias D, De Baere T, Sideris L and Ducreux M. Regional chemotherapeutic techniques for liver tumors: current knowledge and future directions. Surg Clin N Am 2004; 84: 607-625

71. Clavien PA, Selzner N, Morse M et al. Downstaging of hepatocellular carcinoma and liver metastases from colorectal cancer by selective intra-arterial chemotherapy. Surgery 2002; 131: 433-442

72. Kemeny N, Jarnagin W, Paty P et al. Phase I trial of systemic oxaliplatin combination chemotherapy with hepatic arterial infusion in patients with unresectable liver metastases from colorectal cancer. J Clin Oncol 2005; 23:48884896

73. Fernandez FG, Ritter J, Goodwin JW, Linehan DC, Hawkins WG and Strasberg SM. Effect of steatohepatitis associated with irinotecan or oxaliplatin pre-treatment on resectability of hepatic colorectal metastases. J Am Coll Surg 2005; 200: 845853

74. Kemeny N, Huang Y, Cohen A et al. Hepatic arterial infusión of chemotherapy alter resection of hepatic metastases from colorectal cancer. N Eng J Med 1999; 341: 2039-48

75. Adam R, Bismuth H, Castaing D et al. Repeat hepatectomy for colorectal liver metastases. Ann Surg 1997; 225: 51-62

76. Neeleman N, Andersson R. Repeated liver resection for recurrent liver cancer. Br J Surg 1996; 83: 893-901. 